\title{
Treatment Outcome and Prognostic Factors for Pediatric Medulloblastoma Patients: The Egyptian National Cancer Institute Experience
}

\author{
Ehab Elkest, Amr Amin, Mohamed Zaza \\ Radiation Oncology and Nuclear Medicine Department, National Cancer Institute, Cairo University, Cairo, Egypt \\ Email:amr.amin@nci.cu.edu.eg
}

How to cite this paper: Elkest, E., Amin, A. and Zaza, M. (2017) Treatment Outcome and Prognostic Factors for Pediatric Medulloblastoma Patients: The Egyptian National Cancer Institute Experience. Journal of Cancer Therapy, 8, 699-713. https://doi.org/10.4236/jct.2017.88061

Received: June 30, 2017

Accepted: July 28, 2017

Published: August 1, 2017

Copyright $\odot 2017$ by authors and Scientific Research Publishing Inc. This work is licensed under the Creative Commons Attribution International License (CC BY 4.0).

http://creativecommons.org/licenses/by/4.0/

\begin{abstract}
Purpose: To evaluate treatment outcomes and prognostic factors of pediatric Medulloblastoma (MB) patients treated by adjuvant post-operative riskadapted radiotherapy (RT) and chemotherapy (CT). Patients and Methods: A retrospective analysis was conducted based on medical records of pediatric patients with pathologically confirmed MB treated between 2006 and 2013 at the National cancer Institute (NCI), Egypt. Various patients' and disease characteristics, treatment details and outcome data were reviewed. Results: Fifty patients' records were included in the analysis with a median age of 6 years at diagnosis (range 3 - 18). According to the Chang staging system; 38\%, 44\%, $4 \%$, and $14 \%$ were $\mathrm{M} 0, \mathrm{M} 1, \mathrm{M} 2$, and $\mathrm{M} 3$, respectively. All patients underwent primary surgery; gross total resection (with no residual) in $38 \%$, near total resection (with residual $\leq 1.5 \mathrm{~cm}^{2}$ ) in $8 \%$, subtotal resection (with residual $>1.5$ $\mathrm{cm}^{2}$ ) in $34 \%$, and $20 \%$ had only biopsy. All patients were treated by riskadapted craniospinal irradiation (CSI); high-risk patients were treated by CSI $36 \mathrm{~Gy} / 20$ fractions over 4 weeks followed by posterior fossa (PF) boost 18 Gy/10 fractions over 2 weeks ( $180 \mathrm{cGy}$ per fraction), while standard-risk patients were treated by CSI 23.4 Gy/13 fractions over 2 and half weeks followed by PF boost $30.6 \mathrm{~Gy} / 17$ fractions over 3 and half weeks. Median overall treatment time (OTT) was 52 days. All patients received adjuvant CT; 47 patients (94\%) received concomitant chemo radiotherapy (CCRT), while 4 patients (8\%) only received neoadjuvant CT (NB: only one patient received all neoadjuvant, concomitant and adjuvant CT). With a median follow up time of 32.5 months, ranging from 6 to 104 months, the whole group estimates of the overall survival (OS) at 1,3 , and 5 years were $83 \%, 70 \%$, and $64 \%$, respectively, while, the progression-free survival (PFS) rates at 1,3 , and 5 years were $79 \%, 62 \%$, and $57 \%$ respectively. Four patients relapsed. Neural-axis was the commonest site of relapse ( 3 patients). Both risk groups were equally represented in relapsed patients ( 2 standard risk \& 2 high risk patients) and relapse took place within 2 years. In univariate analysis, performance status,
\end{abstract}


extent of surgery, and post-operative residual tumor size were significant prognostic factors for OS. On the other hand, factors which affected the PFS included gender, extent of surgery, and post-operative residual tumor. Conclusion: Neural-axis relapse was the commonest site of relapse for pediatric MB patients. Extent of surgical resection, post-operative residual tumor, and gender are powerful prognostic factors. Maximal safe resection is the standard surgical approach for MB patients to achieve cure.

\section{Keywords}

Pediatric Medulloblastoma, Craniospinal Irradiation, Treatment Outcome, Prognostic Factors

\section{Introduction}

Medulloblastoma (MB) is a disease that predominantly occurs in infants and children, and is the most-common type of pediatric malignant brain tumor, accounting for about $20 \%$ of all childhood brain cancers [1].

In the pathology registry of the National Cancer Institute (NCI) Egypt, it constitutes $13.4 \%$ among all CNS tumors, the second most common tumor following malignant glioma (56\%) [2].

$\mathrm{MB}$ is a type of childhood primitive neuro ectodermal tumors (PNET). The incidence appears to occur in two peaks; the first peak is between 5 - 9 years and the second peak is between 20 - 30 years. The cell of origin is controversial, but probably it originates from germ native neuro-epithelial cells in the roof of the fourth ventricle. The typical location of $\mathrm{MB}$ is in the cerebellum (posterior vermis) (94\%) and may encroach on the fourth ventricle. It commonly disseminates through the subarachnoid space through cerebrospinal fluid (CSF).

MB often presents with manifestations of increased intracranial pressure (headache and morning vomiting) due to obstructive hydrocephalus, which result from compression of the fourth ventricle. Seventy to $90 \%$ of patients with MB present with a history of headache, emesis, and lethargy, these symptoms are generally intermittent and subtle.

$\mathrm{MB}$ patients require full staging of the neural axis, including contrast-enhanced magnetic resonance imaging (MRI) of the brain and full spine and CSF cytological examination, due to high incidence of CSF dissemination.

At present, pediatric $\mathrm{MB}$ is divided into two risk groups: Average-risk patients: are those diagnosed when they are older than the age of 3 years with no metastases (M0) and totally or near-totally resected disease $(<1.5 \mathrm{~cm}$ residual) on postoperative MRI or CT scan; or high-risk patients not fulfilling the criteria mentioned above[3].

There are many pediatric $\mathrm{MB}$ treatment protocols however gross total resection followed by risk adaptive CSI (23.4 - 36 Gy to whole neural axis followed by primary tumor site boost up to $54-55.8 \mathrm{~Gy}$ ) is the current treatment standard in pediatric patients who are over 3 years old. 
Chemotherapy as part of the initial treatment was used to be reserved for patients with disseminated disease. However it is currently incorporated into regimens of all patients as it allows for reduction of CSI dose and its subsequent long term side effects.

The survival rate for pediatric patients with $\mathrm{MB}$ has increased significantly following improvements in imaging modalities, surgical techniques, risk adaptive CSI and the incorporation of active chemotherapeutic regimens. The use of these modalities in modern therapeutic protocols has resulted in a cure rate of approximately $70 \%-75 \%$ among children aged $\geq 3$ years [4] [5].

This study aimed at evaluating the treatment outcome and prognostic factors for pediatric MB patients treated at the NCI, Cairo University, Egypt.

\section{Patients and Methods}

This is a retrospective study that included pediatric patients with pathologic diagnosis of MB treated at the RT Department, NCI, Cairo University from January 2006 to December 2013. The study received approval from ethical committee of NCI. Patients above the age of 18 years were excluded.

\subsection{Data Collection}

Data were collected and written in a data collection sheet. Data sheet included the following information:

Patients' related data (name, hospital number, phone number, RT number, date of birth geographical region of residence, date and age at diagnosis, Gender, family history, presenting symptoms, performance status, and neurological deficit at presentation).

Tumor related data including (histopathological grade, initial imaging studies of the brain and spine, CSF dissemination, size of residual after surgery, and risk stratification).

Treatment related data (initial use of ventriculo-peritoneal (VP) shunt, extent of surgery, use and sequencing of RT and CT; RT doses to the whole brain and the neural axis, total PF dose, response to treatment and additional use of surgery, RT and/or CT in case of relapse).

Outcome data including, OS and DFS measured from the date of pathologic diagnosis. Failures at the primary site PF, the brain, the spine, the meninges (widespread leptomeningeal disease) and/or at extra neural sites (primarily bone) were recorded as the only site of first failure or as a component of first failure. Failure included recurrence or progression of initial disease or relapse in a site free of disease at presentation. The time of failure was determined as the date at which radiologic or biopsy confirmation of relapse at one of these sites occurred.

\subsection{Statistical Analysis}

Data were analyzed using SPSS win statistical package version 21. Numerical data were expressed as mean and standard deviation (SD), median and range as 
appropriate. Qualitative data were expressed as frequency and percentage. Chisquare (Fisher's exact) test was used to examine the relation between qualitative variables as appropriate. Logistic regression model was done to predict effect of different independent factors on patient response to treatment through calculating odds ratio and its $95 \%$ confidence interval (CI). Survival analysis was done using Kapler-Meier method with log rank test for comparison. Multivariate analysis was done by Cox regression model to test for independent prognostic effect of statistically significant variables on univariate level with calculating hazard ratio and its $95 \%$ CI. Correction of P value was done using Benferroni adjustment to avoid hyperinflation of type 1 error resulting from multiple comparisons. $\mathrm{P}$ value $\leq 0.05$ was considered significant and all tests were 2 tailed. OS was calculated from date of accurate diagnosis till date of death or last follow up. PFS was calculated from date of start of treatment (date of surgery) till date of relapse, death or last follow up.

\section{Results}

Between 2006 and 2013, the records of 50 pediatric MB patients were analyzed. Median age was 6 years (range 3 - 18 years), 29 males and 21 females. The cardinal symptom at presentation was vomiting $(74 \%)$, followed by headache (64\%). Other symptoms as blurring of vision, cranial nerve affection, and gait disturbance occurred with less percentages. According to the Chang staging system; $38 \%, 44 \%, 4 \%$, and $14 \%$ were M0, M1, M2, and M3, respectively, CSF dissemination was found in $60 \%$. High risk patients $\left(>1.5 \mathrm{~cm}^{2}\right.$ residual, or $\left.\mathrm{M}+\right)$ comprised $78 \%(39 / 50)$ of the studied patients compared to $22 \%(11 / 50)$ standard risk patients $\left(\leq 1.5 \mathrm{~cm}^{2}\right.$ residual, and $\left.\mathrm{M} 0\right)$. Median tumor size was $4.5 \mathrm{~cm}$, ranging from 2 to $9 \mathrm{~cm}$ (Table 1 ).

\subsection{Surgery}

All 50 patients underwent an attempt for total resection to the extent compatible with good neurological outcome. Postoperative imaging modalities included CT scan and/or MRI of the brain and spine and CSF cytological examination were performed for all the patients. Tumor resection was graded as: 1) Gross total resection (no areas of residual disease) 38\% (19/50), 2) Near total resection (residual $\left.\leq 1.5 \mathrm{~cm}^{2}\right) 8 \%(4 / 50)$, 3) Subtotal resection (residual $>1.5 \mathrm{~cm}^{2}$ ) $34 \%(17 / 50)$, or otherwise considered as a biopsy $20 \%(10 / 50)$ (Table 1$)$.

\subsection{Radiation Therapy (RT)}

All patients received adjuvant RT according to risk stratification. High risk patients were treated with CSI 36 Gy in 20 fractions over 4 weeks (180 cGy per fraction) followed by PF boost 18 Gy in 10 fractions over 2 weeks (180 cGy per fraction), while standard risk patients were treated with CSI 23.4 Gy in 13 fractions over 2 and half weeks ( 180 cGy per fraction) followed by PF boost $30.6 \mathrm{~Gy}$ in 17 fractions over 3 and half weeks (180 cGy per fraction). Median (OTT) was 
Table 1. Clinical and treatment characteristics.

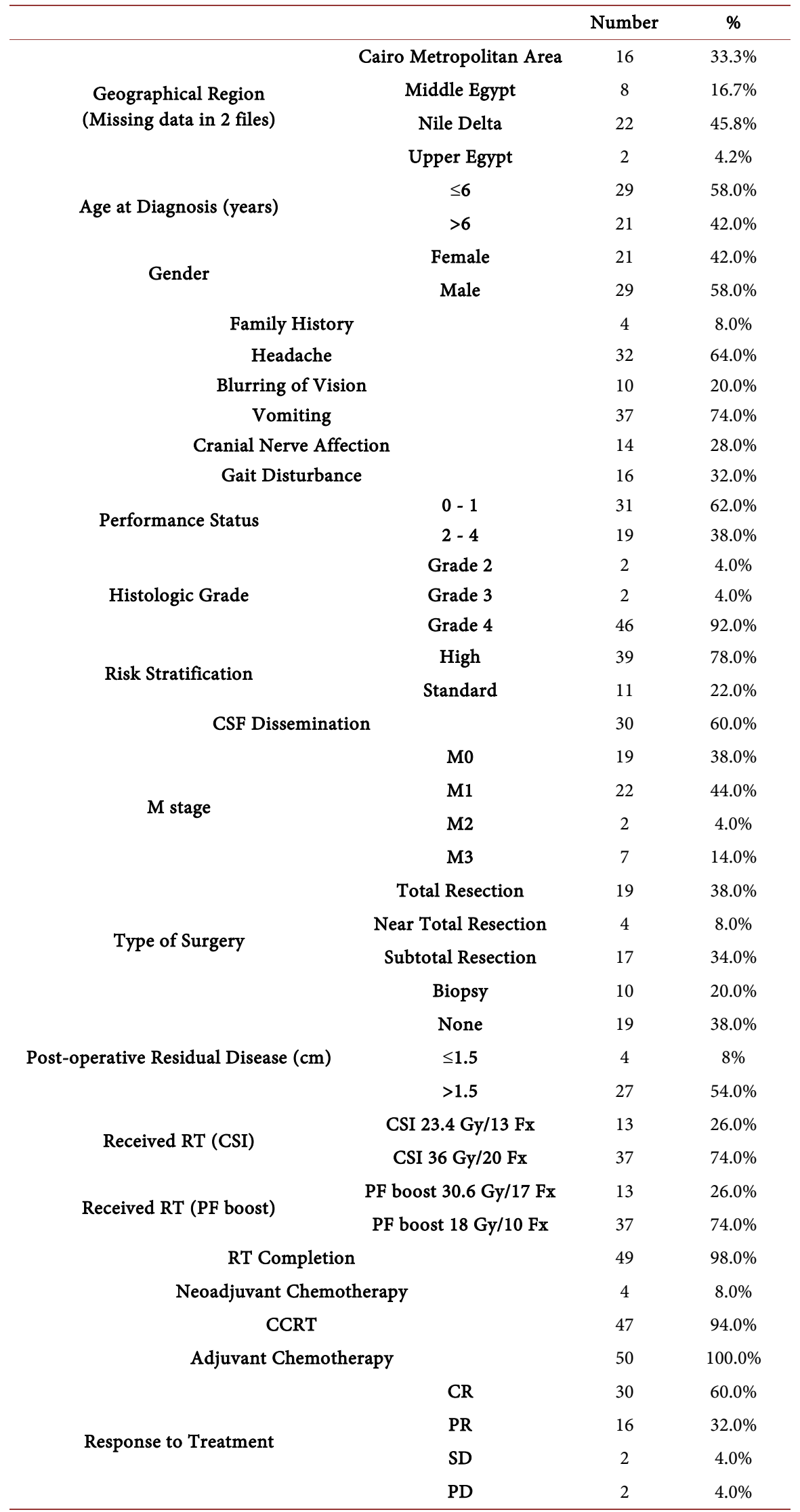


52 days. The CSI technique was similar for all patients and the PF boost was delivered via parallel-opposed photon beams or using a CT-based, multi-field, conformal approach. CSI was performed in the prone position using parallel-opposed lateral cranial fields that abutted a posterior spinal field. Field junctions were changed every five treatments to avoid overdose of the spinal cord. Usually, the cranial field length was decreased by $2 \mathrm{~cm}$ each $10 \mathrm{~Gy}$ with subsequent increase in the upper spinal field length with no shift of the iso-center. If there were two spinal fields, the lower field length was decreased keeping the corresponding skin gap. It is therefore possible for the thyroid gland to get exit dose from the spine field with a new junction change, even if the original spinal field did not exit or diverge into the thyroid gland. Patients were treated using a 6-MV linear accelerator.

\subsection{Chemotherapy}

All patients received CT; concurrent with RT (vincritine) (94\%) and adjuvant CT (100\%), whereas, 4 patients ( $8 \%$ ) only received neoadjuvant CT (i.e. before RT). (NB: only one patient received neoadjuvant, concomitant, and adjuvant CT).

\subsection{Response to Treatment}

Assessment was done 6 months after adjuvant CT. In $92 \%$ of cases there was tumor response $60 \% \mathrm{CR}$ and $32 \% \mathrm{PR}$ (Table 1).

Only geographical region, gender, performance status, extent of surgery, and postoperative residual showed statistically significant correlation with response to treatment on univariate analysis (Table 2). Complete response (CR) was higher in patients from Metropolitan Cairo (87.5\%), and in female patients (71\%). Patients with PS 0-2 who reached CR were (74\%) compared to (42\%) in patients with PS 3-4. Patients who underwent gross total resection had the best CR (95\%), followed by near total \& subtotal resection (52\%), then biopsy (20\%) (adjusted $\mathrm{P}$ value $<0.001$ ). In the same way, patients with no post-operative residual had $95 \%$ CR compared with $42 \%$ in those with residual tumor (adjusted $\mathrm{P}$ value $<0.001)$. Factors that were not statistically significant included: age, family history, initial symptoms and signs, risk stratification, tumor size, CSF dissemination, $\mathrm{M}$ stage, VP shunt, RT and CT, and overall treatment time.

On multivariate analysis only post-operative residual tumor was significantly correlated with response to treatment statistically with 25 times higher risk (OR 24.9, 95\% CI 2.9 - 46.9, P value 0.003 ).

\subsection{Survival and Patterns of Relapse}

With a median follow-up of 32.5 (range 6 - 104) months, four patients relapsed after treatment. One patient had distant relapse, and was treated with RT. Two patients had local relapse, both were treated with palliative CT, and one of them received palliative RT in addition. One patient had both local \& spinal relapses, and was treated with palliative CT. Seventeen patients died of their disease (Table 3). 
Table 2. Response to treatment.

\begin{tabular}{|c|c|c|c|c|c|c|}
\hline & & \multicolumn{4}{|c|}{ Response to Treatment } & \multirow[t]{3}{*}{ Adjusted P Value } \\
\hline & & \multicolumn{2}{|c|}{ Not CR } & \multicolumn{2}{|c|}{ CR } & \\
\hline & & No. & $\%$ & No. & $\%$ & \\
\hline \multirow{3}{*}{ Geographical Region } & $\begin{array}{c}\text { Upper \& Middle } \\
\text { Egypt }\end{array}$ & 5 & $50.0 \%$ & 5 & $50.0 \%$ & \multirow{3}{*}{0.041} \\
\hline & $\begin{array}{l}\text { Metropolitan } \\
\text { Cairo }\end{array}$ & 2 & $12.5 \%$ & 14 & $87.5 \%$ & \\
\hline & Nile Delta & 11 & $50.0 \%$ & 11 & $50.0 \%$ & \\
\hline \multirow{2}{*}{ Gender } & Female & 6 & 28.6 & 15 & $71.4 \%$ & \multirow{2}{*}{0.035} \\
\hline & Male & 17 & $58.6 \%$ & 12 & $41.4 \%$ & \\
\hline \multirow{2}{*}{ Performance status } & PS 0 - 2 & 8 & $25.8 \%$ & 23 & $74.2 \%$ & \multirow{2}{*}{0.023} \\
\hline & PS $3-4$ & 11 & $57.9 \%$ & 8 & $42.1 \%$ & \\
\hline \multirow{3}{*}{ Type of Surgery } & $\begin{array}{l}\text { Gross Total } \\
\text { Resection }\end{array}$ & 1 & $5.3 \%$ & 18 & $94.7 \%$ & \multirow{3}{*}{$<0.001$} \\
\hline & $\begin{array}{l}\text { Subtotal or Near } \\
\text { Total Resection }\end{array}$ & 10 & $47.6 \%$ & 11 & $52.4 \%$ & \\
\hline & Biopsy & 8 & $80.0 \%$ & 2 & $20.0 \%$ & \\
\hline \multirow{4}{*}{$\begin{array}{c}\text { Presence of } \\
\text { post-operative residual }\end{array}$} & No & 1 & $5.3 \%$ & 18 & $94.7 \%$ & \multirow{4}{*}{$<0.001$} \\
\hline & Present & 18 & $58.1 \%$ & 13 & $41.9 \%$ & \\
\hline & Yes & 16 & $34.0 \%$ & 31 & $66.0 \%$ & \\
\hline & Grades 1 - 4 & 1 & $33.3 \%$ & 2 & $66.7 \%$ & \\
\hline
\end{tabular}

Table 3. Survival and pattern of relapse of the studied patients.

\begin{tabular}{|c|c|c|}
\hline & & Number \\
\hline \multirow{4}{*}{ Follow Up Status } & Alive Free & 27 \\
\hline & Alive with Disease & 5 \\
\hline & Deceased Free & 1 \\
\hline & Deceased with Disease & 17 \\
\hline \multirow{2}{*}{ OS Status } & Alive & 32 \\
\hline & Deceased & 18 \\
\hline \multicolumn{2}{|c|}{ Local Relapse } & 3 \\
\hline \multicolumn{2}{|c|}{ Spinal Relapse } & 1 \\
\hline \multicolumn{2}{|c|}{ Distant Relapse } & 1 \\
\hline \multicolumn{2}{|c|}{ Relapse } & 4 \\
\hline
\end{tabular}

\subsection{Overall Survival}

For the whole group, the surviving proportion estimates at 1,3 , and 5 years were $83 \%, 70 \%$, and $64 \%$, respectively. In the univariate analysis, geographical region $(P=0.016)$, performance status $(P=0.026)$, extent of surgery $(P=0.010)$, and post-operative residual tumor size $(\mathrm{P}=0.015)$ were significant prognostic factors for OS (Table 4, Figures 1-3), while other factors were not statistically significant. 
Table 4. Univariate analysis of different prognostic variables for overall survival.

\begin{tabular}{|c|c|c|c|c|c|c|c|}
\hline & & \multirow{2}{*}{ No. } & \multicolumn{3}{|c|}{$\%$ Surviving at } & \multirow{2}{*}{$\begin{array}{c}\text { Median Survival } \\
\text { Estimate (months) }\end{array}$} & \multirow{2}{*}{$P$-value } \\
\hline & & & 1 year & 3 years & 5 years & & \\
\hline \multirow{2}{*}{ Whole Group } & & 50 & 83.2 & 70.1 & 64.3 & 97.1 & * \\
\hline & $\begin{array}{c}\text { Upper \& Middle } \\
\text { Egypt }\end{array}$ & 10 & 54.9 & 41.1 & NR & 12 & \multirow{3}{*}{0.016} \\
\hline \multirow[t]{2}{*}{$\begin{array}{l}\text { Geographical } \\
\text { Region }\end{array}$} & $\begin{array}{l}\text { Metropolitan } \\
\text { Cairo }\end{array}$ & 16 & 86.5 & 86.5 & 86.5 & NR & \\
\hline & Nile Delta & 22 & 90.7 & 72 & 60 & 74.9 & \\
\hline \multirow{3}{*}{$\begin{array}{l}\text { Performance } \\
\text { Status }\end{array}$} & $<2$ & 31 & 89.6 & 85.9 & 82 & 97.1 & \multirow{2}{*}{0.026} \\
\hline & $\geq 2$ & 19 & 73.3 & 53.3 & 42.7 & 58 & \\
\hline & $\begin{array}{c}\text { Total } \\
\text { Resection }\end{array}$ & 19 & 89.2 & 89.2 & 89.2 & NR & \multirow{4}{*}{0.010} \\
\hline \multirow[t]{3}{*}{$\begin{array}{l}\text { Type of } \\
\text { Surgery }\end{array}$} & $\begin{array}{l}\text { Subtotal or Near } \\
\text { Total Resection }\end{array}$ & 21 & 84.4 & 66.8 & 66.8 & 97.1 & \\
\hline & Biopsy & 10 & 70 & 42 & 21 & 28 & \\
\hline & No & 20 & 89.7 & 89.7 & 89.7 & NR & \\
\hline \multirow{2}{*}{$\begin{array}{l}\text { Post-operativ } \\
\text { e Residual }\end{array}$} & Present & 30 & 79.1 & 58 & 48.3 & 58 & \multirow[t]{2}{*}{0.015} \\
\hline & $18 \mathrm{~Gy} / 10 \mathrm{Fx}$ & 37 & 77.5 & 58.5 & 58.5 & 97.1 & \\
\hline
\end{tabular}

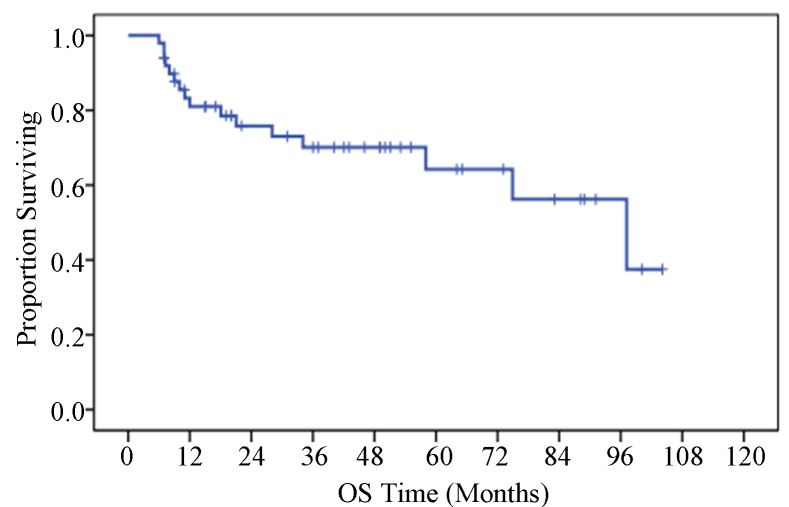

$\neg$ Survival Function + Censored

Figure 1. OS for whole group.

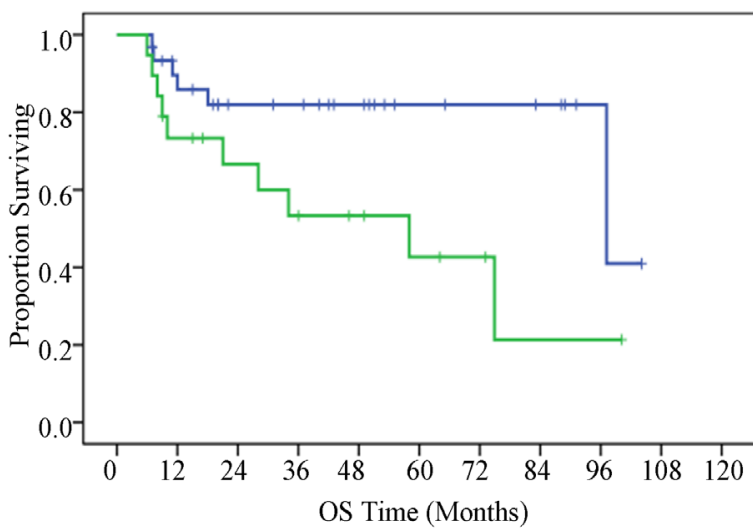

Performance status $\Omega<2$
$\Omega>=2$ $+<2$-Censored $+>=2$-Censored

Figure 2. OS analysis according to Performance status.

On multivariate analysis using Cox-Regression hazard model only extent of surgery was significantly correlated with OS statistically; patients who under- 
went biopsy had a hazard ratio (HR) of 12.8 with $95.0 \%$ CI $2.3-70.9$ and P value 0.003 .

\subsection{Progression Free Survival (PFS)}

In the univariate analysis, gender $(P=0.032)$, extent of surgery $(P=0.036)$, and post-operative residual tumor size $(P=0.013)$ were significantly correlated with PFS statistically (Table 5, Figures 4-6), while other factors were not statistically significant.

On multivariate analysis only gender and presence of post-operative residual tumor, were statistically significant by Cox-Regression hazard model. Hazard ratio was 3.6 with 95\% CI 1.2 - 11 and p value 0.024 for gender and 3.5 with $95 \%$ CI 1 - 12 and P value 0.049 for post op residual.

\section{Discussion}

The standard of care for pediatric patients with MB includes; a combination of maximal safe resection, risk adaptive CSI followed by boost to PF, and adjuvant CT. Patients who undergo a gross total or subtotal resection for non-metastatic

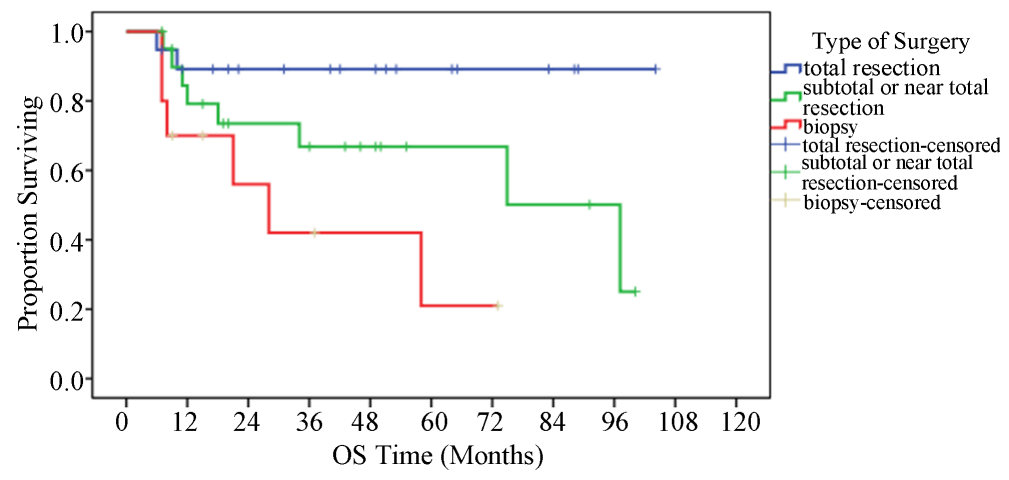

Figure 3. OS analysis according to type of surgery.

Table 5. Univariate analysis of different prognostic variables for progression free survival (PFS).

\begin{tabular}{|c|c|c|c|c|c|c|c|}
\hline & & \multirow{2}{*}{ No. } & \multicolumn{3}{|c|}{$\%$ Surviving at } & \multirow{2}{*}{$\begin{array}{c}\text { Median } \\
\text { Survival } \\
\text { Estimate (months) }\end{array}$} & \multirow{2}{*}{ P-value } \\
\hline & & & 1 year & 3 years & 5 years & & \\
\hline Whole Group & & 50 & 79.2 & 62.2 & 57 & 74.9 & * \\
\hline \multirow{2}{*}{ Gender } & Female & 21 & 85.2 & 78.7 & 78.7 & NR & \multirow{2}{*}{0.032} \\
\hline & Male & 29 & 74.8 & 49.8 & 39.9 & 28 & \\
\hline \multirow{4}{*}{ Type of Surgery } & Total Resection & 19 & 83.9 & 83.9 & 83.9 & NR & \multirow{4}{*}{0.036} \\
\hline & Subtotal or & & & & & & \\
\hline & $\begin{array}{l}\text { Near Total } \\
\text { Resection }\end{array}$ & 21 & 80 & 52.9 & 58.7 & 74.9 & \\
\hline & Biopsy & 10 & 70 & 42 & 21 & 28 & \\
\hline \multirow{2}{*}{$\begin{array}{c}\text { Post-operative } \\
\text { Residual }\end{array}$} & No & 20 & 84.7 & 84.7 & 84.7 & NR & \multirow{2}{*}{0.013} \\
\hline & Present & 30 & 75.7 & 48.5 & 40.4 & 34 & \\
\hline
\end{tabular}




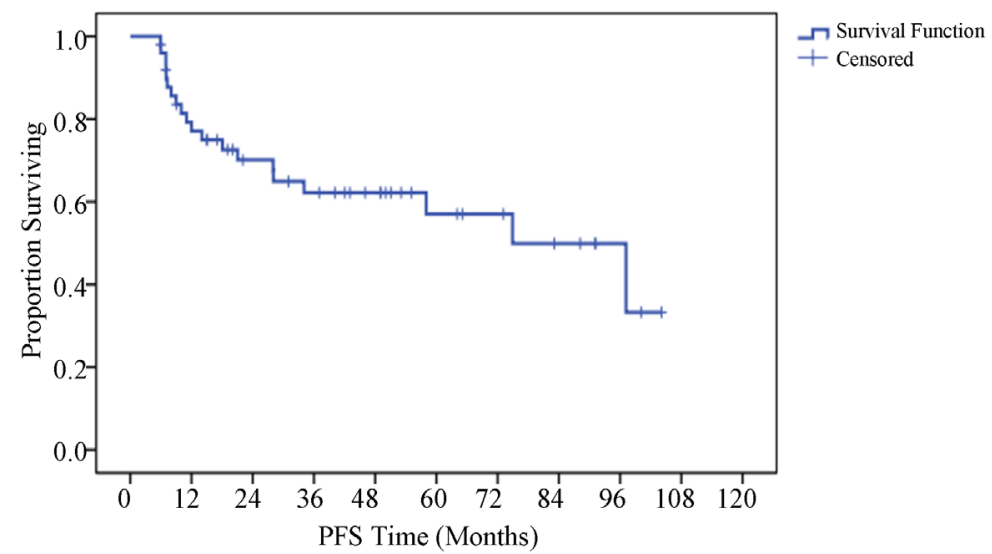

Figure 4. PFS for whole group.

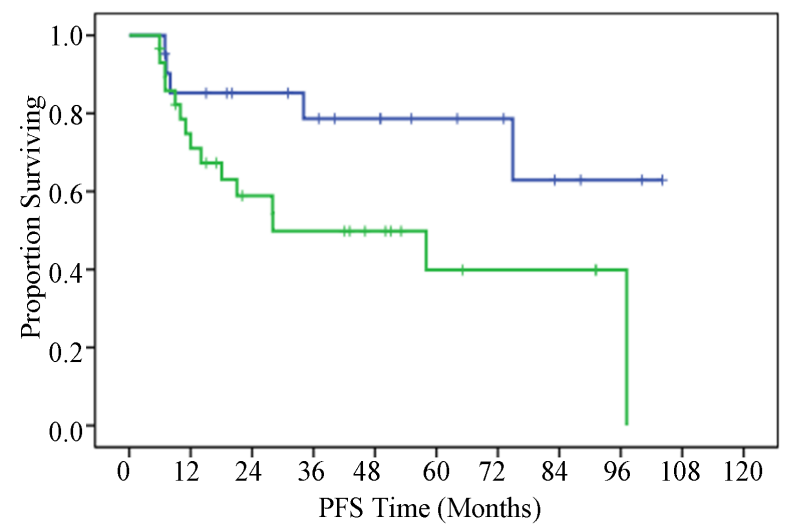

Figure 5. PFS analysis according to gender.

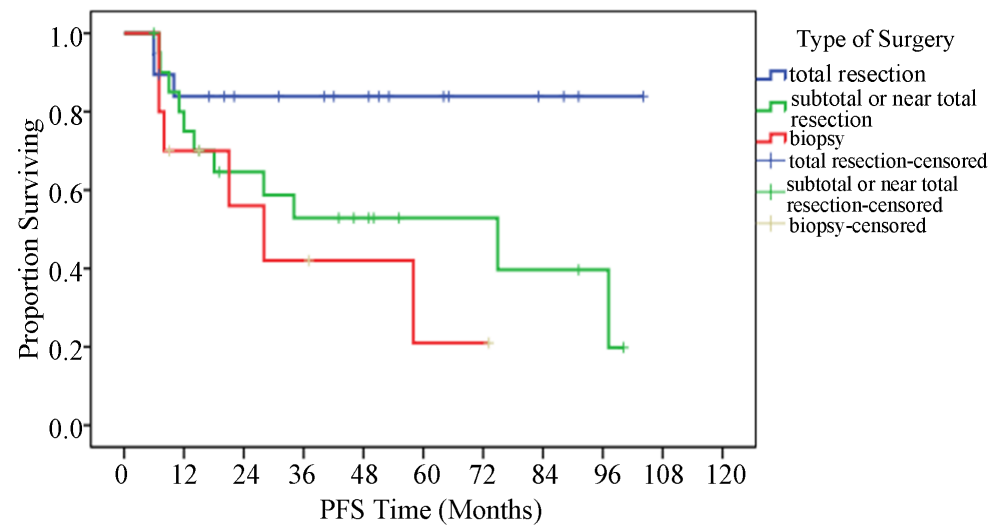

Figure 6. PFS analysis according to type of surgery.

MB have a better outcome than those who have a biopsy alone followed by RT, with reported five-year survival of $(69 \%-89 \%$ versus $27 \%-43 \%)$ for patients with gross total or subtotal resection compared to biopsy alone [6] [7].

\subsection{Demographic Data}

In this study, 29 out of 50 patients were males (58\%) 1.38:1. This is consistent with national and international studies reporting a slight male predominance [8] 
[9]. In similar national studies, males constituted (57\%) in previous NCI study [10], and (51.4\%) in a larger Kasr Al Aini study [11]. In a meta-analysis of 10,582 childhood brain tumors, male to female ratio was reported to be 1.29:1 [12]. On the other hand, other studies reported a slight female predominance [13] [14].

\subsection{Clinical Data}

In this study, vomiting was the most frequent presentation followed by headache, $74 \%$ and $64 \%$, respectively. Findings are consistent with Kasr Al-Aini study, (77.4\% and $75.6 \%$, respectively) [11] and an international meta-analysis of 4171 children with intracranial tumors (75\%, and 67\% respectively) [15].

As regards $\mathrm{M}$ stage, M0/M1 patients in this series had a higher 5-year PFS (61\%) compared to $36 \%$ for M2-M4. Results are comparable to other studies where non-metastatic patients (M0) had a significantly higher 5-year PFS (70\% $78 \%$ ) versus $57 \%$ for M1 and 20\% - 40\% for M2, M3, or M4 disease [16] [17].

As regards risk stratification, in this study, 39 out of 50 (78\%) patients were assigned to the high-risk group, 30 out of $50(60 \%)$ patients had positive CSF cytology and M0 patients were only $38 \%$. This is different from internationally reported 50\% - 70\% standard-risk, 20\% - 30\% CSF dissemination and 78\% M0 patients [10] [18] [19]. This may be explained by the deficiency of pediatric oncology and pediatric neurosurgery departments in Nile Delta region, leading to suboptimum surgical resection and late presentation at the NCI with relatively advanced stage.

\subsection{Treatment Data}

Standard therapy includes maximal safe resection of the tumor, RT to the entire craniospinal axis with boost to PF (for patients $>3$ years), followed by adjuvant CT. Complete resection should be performed if possible as several studies have correlated outcome with extent of resection and volume of residual tumor. In this study (based on postoperative neural-imaging), gross total/near total resection subtotal resection and biopsy were done in $23(46 \%), 17(34 \%)$, and 10 (20\%) patients, respectively. Results are comparable to other national studies (25\%, $61 \%$, and $13 \%$, respectively) [10].

In this study, 43 (86\%) patients underwent VP shunt in the peri-operative period. Results are comparable with national \& international percentage of $96 \%$.

Adjuvant CT has been shown to improve outcome in children with MB. The efficacy of $\mathrm{CT}$ in the treatment of $\mathrm{MB}$ has been assessed previously in two large randomized trials conducted by the International Society of Pediatric Oncology [20]. The addition of CT for high-risk patients seems to improve their survival and has led to better outcome even in average-risk patients. In this study, all patients were treated with CT; CCRT (94\%), adjuvant CT (100\%), while only $8 \%$ were treated with neoadjuvant CT (i.e. before RT) compared with only $67 \%$ in earlier national studies [10]. This may be explained by the recent increased role of $\mathrm{CT}$ in treatment of $\mathrm{MB}$ patients, and its inclusion as a standard of care in in- 
ternational protocols [4] [21] [22] [23] [24]. In the POD8631/CCG923 trial, the effect of CSI without CT was investigated, higher numbers of early failures were reported, 5-year event free survival was 52\%, prompt premature closure of the study prevented confirmation of statistical significance of the results on long-term follow-up and CT has been added in subsequent trials [25].

\subsection{Survival}

In this study, the OS rates at 3 and 5 years were $70 \%$ and $64 \%$, respectively. The latter is comparable to other studies where it ranged from 60\% [26] [27] [28] to $85 \%$ [29] [30] [31] [32] [33]. In this study, PFS rates at 3 and 5 years were $62 \%$ and $57 \%$, respectively which is comparable to other studies where it ranged from $40 \%$ [21] [30] [31] to $70 \%$ [17] [22] [32].

\subsection{Prognostic Factors}

Factors which affected the OS included geographical region $(\mathrm{P}=0.016)$, performance status $(P=0.026)$, extent of surgery $(P=0.010)$, post-operative residual tumor size $(\mathrm{P}=0.015)$, and grade of headache during treatment (acute complication) $(\mathrm{P}=0.001)$. While factors which affected the PFS included female gender $(P=0.032)$, extent of surgery $(P=0.036)$, post-operative residual tumor size ( $P$ $=0.013)$, and grade of headache during treatment (acute complication) $(\mathrm{P}=$ $0.015)$.

Gender is a controversial prognostic factor in pediatric series. In this study, female gender had significant favorable impact on PFS which is comparable to other studies [34] [35] [36].

In this study, the interval between surgery and the start of RT did not show influence on survival. Results are comparable to previous national study [10].

Certain studies have shown a correlation between completion of RT in the prescribed OTT and improved PF control [36] while other studies did not prove that correlation [10] [20]. In this study, OTT did not show significance for better outcome $(\mathrm{P}=0.194)$. Interesting to note is that the OTT at NCI has increased from a reported median of 45 days (during the period from 1997 to 2004) to 52 days in this study (during the period from 2006 to 2013) and that did not lead to poorer results.

\subsection{Conclusions}

Neural-axis relapse is the most common site of relapse for pediatric MB patients. Extent of surgical resection, post-operative residual tumor, and gender were powerful prognostic factors. Maximal safe resection is the standard surgical approach for MB patients to achieve cure.

The role of interval between surgery and the start of RT and adjuvant highdose CT especially for high-risk pediatric MB patients require further investigation. Late recurrences are not rare; therefore, long-term follow-up is needed.

Pediatric neurosurgery is a subspecialty that needs further advanced training programs to be able to follow the rapid-pace advancements in this field. In the 
same way, departments/centers of pediatric oncology need to be established and developed in Nile Delta cities to help for early detection and proper management of pediatric cancer patients in this region. The absence of this specialty in the cancer centers of Nile Delta leads to mismanagement of those patients, which leads to their presentation to NCI with advanced stage to the extent that it significantly affected the OS in this study.

\section{References}

[1] Pui, C.H., Gajjar, A.J., Kane, J.R., Qaddoumi, I.A. and Pappo, A.S. (2011) Challenging Issues in Pediatric Oncology. Nature Reviews Clinical Oncology, 8, 540-549. https://doi.org/10.1038/nrclinonc.2011.95

[2] Mokhtar, N., Gouda, I. and Adel, I. (2007) Cancer Pathology Registry 2003-2004 and Time Trend Analysis. Department of Pathology, NCI.

[3] Ellison, D.W., Clifford, S.C. and Gajjar, A. (2003) What's New in Neuro-Oncology? Recent Advances in Medulloblastoma. European Journal of Paediatric Neurology, 7, 53-66.

[4] Packer, R.J., et al. (2006) Phase III Study of Craniospinal Radiation Therapy Followed by Adjuvant Chemotherapy for Newly Diagnosed Average-Risk Medulloblastoma. Journal of Clinical Oncology, 24, 4202-4208. https://doi.org/10.1200/JCO.2006.06.4980

[5] Gajjar, A., et al. (2006) Risk-Adapted Craniospinal Radiotherapy Followed by HighDose Chemotherapy and Stem-Cell Rescue in Children with Newly Diagnosed Medulloblastoma (St Jude Medulloblastoma-96): Long-Term Results from a Prospective, Multicentre Trial. The Lancet Oncology, 7, 813-820.

[6] Del Charco, J.O., Bolek, T.W., McCollough, W.M., Maria, B.L., Kedar, A., Braylan, R.C., et al. (1998) Medulloblastoma: Time-Dose Relationship Based on a 30-Year Review. International Journal of Radiation Oncology, Biology, Physics, 42, 147-154.

[7] Hughes, E.N., Shillito, J., Sallan, S.E., Loeffler, J.S., Cassady, J.R. and Tarbell, N.J. (1988) Medulloblastoma at the Joint Center for Radiation Therapy between 1968 and 1984. Cancer, 61, 1992-1998. https://doi.org/10.1002/1097-0142(19880515)61:10<1992::AID-CNCR2820611011> 3.0.CO;2-J

[8] Nayil, K., Makhdoomi, R., Ramzan, A., Zahoor, S., Rasool, M., Wani, A., Dhar, A., Mubeen, B., Singh, S., Bhat, R. and Kirmani, A. (2011) Childhood Tumors of the Brain: Demographic Pattern over a Ten-Year Period in the Kashmir Valley. Pediatric Neurosurgery, 47, 31-37. https://doi.org/10.1159/000327143

[9] Nasir, S., Jamila, B. and Khaleeq, S. (2010) A Retrospective Study of Primary Brain Tumors in Children under 14 Years of Age at PIMS, Islamabad. Asian Pacific Journal of Cancer Prevention, 11, 1225-1227.

[10] Khalil, E.M. (2008) Treatment Results of Adults and Children with Medulloblastoma NCI, Cairo University Experience. Journal of the Egyptian National Cancer Institute, 20, 175-186.

[11] El-Gaidi, M.A. (2011) Descriptive Epidemiology of Pediatric Intracranial Neoplasms in Egypt. Pediatric Neurosurgery, 47, 385-395. https://doi.org/10.1159/000337872

[12] Rickert, C.H. and Paulus, W. (2001) Epidemiology of Central Nervous System Tumors in Childhood and Adolescence Based on the New WHO Classification. Child $s$ Nervous System, 17, 503-511. https://doi.org/10.1007/s003810100496 
[13] Lashley, P.M., Clarke, H. and Archer, E.Y. (1991) Primary Pediatric Brain Tumours in Barbados: 10-Year Analysis (1978-1988). Journal of Tropical Pediatrics, 37, 6466. https://doi.org/10.1093/tropej/37.2.64

[14] Olasode, B.J., Shokunbi, M.T. and Aghadiuno, P.U. (2000) Intracranial Neoplasms in Ibadan, Nigeria. East African Medical Journal, 77, 4-8.

[15] Wilne, S., Collier, J., Kennedy, C., Koller, K., Grundy, R. and Walker, D. (2007) Presentation of Childhood CNS Tumours: A Systematic Review and Meta-Analysis. The Lancet Oncology, 8, 685-695.

[16] Jenkin, D., Al Shabanah, M., Al Shail, E., Gray, A., Hassounah, M., Khafaga, Y., et al. (2000) Prognostic Factors for Medulloblastoma. International Journal of Radiation Oncology, Biology, Physics, 47, 573-584.

[17] Zeltzer, P.M., Boyett, J.M., Finlay, J.L., et al. (1999) Metastasis Stage, Adjuvant Treatment, and Residual Tumor Are Prognostic Factors for Medulloblastoma in Children: Conclusions from the Children's Cancer Group 921 Randomized Phase III Study. Journal of Clinical Oncology, 17, 832-834. https://doi.org/10.1200/JCO.1999.17.3.832

[18] Packer, R.J., Rood, B.R. and MacDonald, T.J. (2003) Medulloblastoma: Present Concepts of Stratification into Risk Groups. Pediatric Neurosurgery, 39, 60-67. https://doi.org/10.1159/000071316

[19] Labbe, D., Provencal, M., Lamy, S., et al. (2009) The Flavonols Quercetin, Kaempferol, and Myricetin Inhibit Hepatocyte Growth Factor-Induced Medulloblastoma Cell Migration. Journal of Nutrition, 139, 646-652. https://doi.org/10.3945/jn.108.102616

[20] Yock, T.I., Friedman, H., Kun, L., Kepner, J., Barnes, P. and Tarbell, N.J. (2001) Response to Pre-Radiation Chemotherapy Is Predictive of Improved Survival in High Risk Medulloblastoma: Results from the Paediatric Oncology Group (POG 9031). International Journal of Radiation Oncology, Biology, Physics, 51, 120-121.

[21] Bailey, C.C., Gnekow, A., Wellek, S., et al. (1995) Prospective Randomized Trial of Chemotherapy Given before Radiotherapy in Childhood MB. International Society of Pediatric Oncology (SIOP) and the (German) Society of Paediatric Oncology (GPO): SIOP II. Medical and Pediatric Oncology, 25, 166-178. https://doi.org/10.1002/mpo.2950250303

[22] Strother, D., Ashley, D., Kellie, S.J., et al. (2001) Feasibility of Four Consecutive High-Dose Chemotherapy Cycles with Stem-Cell Rescue for Patients with Newly Diagnosed Medulloblastoma or Supratentorial Primitive Neuroectodermal Tumor after Craniospinal Radiotherapy: Results of a Collaborative Study. Journal of Clinical Oncology, 19, 2696-2704. https://doi.org/10.1200/JCO.2001.19.10.2696

[23] Dhodapkar, K., Dunkel, I.J., Gardner, S., et al. (2002) Preliminary Results of Dose Intensive Pre-Irradiation Chemotherapy in Patients Older than 10 Years of Age with High Risk Medulloblastoma and Supratentorial Primitive Neuroectodermal Tumors. Medical and Pediatric Oncology, 38, 47-48. https://doi.org/10.1002/mpo.1262

[24] Merchant, T.E., Kun, L.E., Krasin, M.J., et al. (2008) Multi-Institution Prospective Trial of Reduced-Dose CSI (23.4 Gy) Followed by Conformal Posterior Fossa (36 Gy) and Primary Site Irradiation (55.8 Gy) and Dose-Intensive Chemotherapy for Average-Risk Medulloblastoma. International Journal of Radiation Oncology, Biology, Physics, 70, 782-787.

[25] Thomas, P.R., Deutsch, M., Kepner, J.L., et al. (2000) Low-Stage Medulloblastoma: Final Analysis of Trial Comparing Standard-Dose with Reduced-Dose Neuraxis Irradiation. Journal of Clinical Oncology, 18, 3004-3011. 
https://doi.org/10.1200/JCO.2000.18.16.3004

[26] Chi, S.N., Gardner, S.L., Levy, A.S., et al. (2004) Feasibility and Response to Induction Chemotherapy Intensified with High-Dose Methotrexate for Young Children with Newly Diagnosed High-Risk Disseminated Medulloblastoma. Journal of Clinical Oncology, 22, 4881-4887. https://doi.org/10.1200/JCO.2004.12.126

[27] Rutkowski, S., Gerber, N.U., von, H.K., et al. (2009) Treatment of Early Childhood Medulloblastoma by Postoperative Chemotherapy and Deferred Radiotherapy. Neuro-Oncology, 11, 201-210. https://doi.org/10.1215/15228517-2008-084

[28] Ashley, D.M., Merchant, T.E., Strother, D., et al. (2012) Induction Chemotherapy and Conformal Radiation Therapy for Very Young Children with Non-Metastatic Medulloblastoma: Children's Oncology Group Study P9934. Journal of Clinical Oncology, 30, 3181-3186. https://doi.org/10.1200/JCO.2010.34.4341

[29] Gajjar, A., Fouladi, M., Walter, A.W., et al. (1999) Comparison of Lumbar and Shunt Cerebrospinal Fluid Specimens for Cytologic Detection of Leptomeningeal Disease in Pediatric Patients with Brain Tumors. Journal of Clinical Oncology, 17, 1825-1828. https://doi.org/10.1200/JCO.1999.17.6.1825

[30] Duffner, P.K., Horowitz, M.E., Krischer, J.P., et al. (1993) Postoperative Chemotherapy and Delayed Radiation in Children Less than Three Years of Age with Malignant Brain Tumors. The New England Journal of Medicine, 328, 1725-1731. https://doi.org/10.1056/NEJM199306173282401

[31] Taylor, R.E., Bailey, C.C., Robinson, K.J., et al. (2005) Outcome for Patients with Metastatic (M2-3) Medulloblastoma Treated with SIOP/UKCCSG PNET-3 Chemotherapy. European Journal of Cancer, 41, 727-734.

[32] Gandola, L., Massimino, M., Cefalo, G., et al. (2009) Hyperfractionated Accelerated Radiotherapy in the Milan Strategy for Metastatic Medulloblastoma. Journal of Clinical Oncology, 27, 566-571. https://doi.org/10.1200/JCO.2008.18.4176

[33] Tarbell, N.J., Friedman, H., Polkinghorn, W.R., et al. (2013) High-Risk Medulloblastoma: A Pediatric Oncology Group Randomized Trial of Chemotherapy before or after Radiation Therapy (POG 9031). Journal of Clinical Oncology, 31, 2936-2941. https://doi.org/10.1200/JCO.2012.43.9984

[34] Sirachainan, N., Nuchprayoon, I., Thanarattanakorn, P., et al. (2011) Outcome of Medulloblastoma in Children Treated with Reduced-Dose Radiation Therapy plus Adjuvant Chemotherapy. Journal of Clinical Neuroscience, 18, 515-519.

[35] Weil, M.D., Lamborn, K., Edwards, M.S. and Wara, W.M. (1998) Influence of a Child's Sex on Medulloblastoma Outcome. JAMA, 279, 1474-1476. https://doi.org/10.1001/jama.279.18.1474

[36] Prados, M.D., Warnick, R.E., Wara, W.M., Larson, D.A., Lamborn, K. and Wilson, C.B. (1995) Medulloblastoma in Adults. International Journal of Radiation Oncology, Biology, Physics, 32, 1145-1152. 
Submit or recommend next manuscript to SCIRP and we will provide best service for you:

Accepting pre-submission inquiries through Email, Facebook, LinkedIn, Twitter, etc. A wide selection of journals (inclusive of 9 subjects, more than 200 journals)

Providing 24-hour high-quality service

User-friendly online submission system

Fair and swift peer-review system

Efficient typesetting and proofreading procedure

Display of the result of downloads and visits, as well as the number of cited articles Maximum dissemination of your research work

Submit your manuscript at: http://papersubmission.scirp.org/

Or contact jet@scirp.org 